\title{
I 40 Molecular MRI of vascular remodeling in a swine model of coronary injury using an elastin-binding contrast agent
} Christian von Bary ${ }^{1}$, Anne Preissel2 ${ }^{2}$, Elmar Spuentrup ${ }^{3}$, Alexandra Keithahn ${ }^{4}$, Nikolaus Schickl ${ }^{1}$, Arno Buecker ${ }^{5}$, Simon Robinson ${ }^{6}$, Joel Lazewatsky ${ }^{6}$, Albert Schoemig ${ }^{1}$, Markus Schwaiger ${ }^{4}$, Joerg Hausleiter ${ }^{1}$ and René M Botnar*4

\begin{abstract}
Address: ${ }^{1}$ Cardiology Division, Technische Universität München, München, Germany, ${ }^{2}$ Center for Preclinical Research, Technische Universität München, München, Germany, ${ }^{3}$ Diagnostic Radiology, Cologne University, Cologne, Germany, ${ }^{4}$ Nuclear Medicine, Technische Universität München, München, Germany, ${ }^{5}$ Diagnostic Radiology, University Saarland, Homburg, Germany and ${ }^{6}$ Bristol-Myers Squibb Medical Imaging, North Billerica, MA, USA

* Corresponding author
\end{abstract}

from I th Annual SCMR Scientific Sessions

Los Angeles, CA, USA. I-3 February 2008

Published: 22 October 2008

Journal of Cardiovascular Magnetic Resonance 2008, I0(SuppI I):A4I doi:I0.I I86/I532-429X-I0-SI-A4 I

This abstract is available from: http://jcmr-online.com/content/I0/SI/A4I

(C) 2008 von Bary et al; licensee BioMed Central Ltd.

\section{Introduction}

Extracellular matrix (ECM) synthesis and degradation plays and important role in the initiation, progression and complication of atherosclerosis and in-stent restenosis but also in aneurysm formation/degradation and graft disease. Enhanced synthesis of ECM typically leads to expansive or constrictive vessel wall remodeling resulting in plaque stability but also arterial stenosis or in-stent restenosis. In contrast, advanced ECM degradation can lead to plaque instability and subsequent plaque rupture as typically observed in patients with acute coronary syndromes. In an animal study of left carotid artery injury, enhanced collagen and elastin formation was found three weeks post balloon angioplasty compared to the noninjured control vessel.

\section{Purpose}

In this study we sought to demonstrate the feasibility of non-invasive MR imaging of vascular remodeling in a swine model of coronary injury using a novel elastinbinding low molecular weight contrast agent, BMS753951 (abstract 12957, AHA 2007: Bristol Myers Squibb, Billerica, MA).

\section{Methods}

Vascular injury was induced in 6 female landrace pigs (30-35 kg) by endothelial denudation (LCX) and stent placement (LAD) or vice versa, followed by a 28 day normal diet. The RCA served as control vessel. Lasered MRlucent prototype stents (Aachen Resonance, Aachen, Germany) were used to allow artifact free imaging of the stent lumen and vessel wall. At day 28, free-breathing coronary MRA and delayed enhancement imaging of the coronary vessel walls was performed using a $1.5 \mathrm{~T}$ MR scanner (Achieva, Philips Medical Systems, NL) pre and after injection of $0.2 \mathrm{mmol} / \mathrm{kg}$ Gd-DTPA. Imaging parameters of the free-breathing ECG triggered and navigator (NAV) gated inversion recovery (IR) segmented gradient echo vessel wall sequence included $\mathrm{FOV}=320 \mathrm{~mm}$, matrix $=$ $256 \times 256$, in-plane resolution $=1.25 \times 1.25 \mathrm{~mm}$, slice thickness $=3 \mathrm{~mm}$, acquisition window $=50 \mathrm{~ms}, \mathrm{TR} / \mathrm{TE}=$ $4.7 \mathrm{~ms} / 1.4 \mathrm{~ms}$, flip angle $=30^{\circ}$, inversion time $=285 \mathrm{~ms}$ (@90 bpm), and slices = 24. Two days later, coronary MRA and delayed enhancement coronary vessel wall imaging were repeated pre and post injection of 0.1 $\mathrm{mmol} / \mathrm{kg}$ BMS753951 until two hours post injection. After completion of MR imaging, x-ray coronary angiography was performed to assess the degree of luminal stenosis in the stented and balloon injured vessel segment. 
Subsequently, animals were euthanized and gadolinium concentration was determined by inductively coupled plasma mass spectrometry (ICP-MS) in the ascending aorta. For objective image analysis, contrast-to-noise ratio (CNR) between vessel wall and blood was determined by manual segmentation of the coronary vessel wall in the stented, balloon injured and control vessels on reformatted images.

\section{Results}

No visually apparent enhancement of the stented, balloon injured and control coronary vessel segments was observed after administration of Gd-DTPA (Figure 1b, e). In contrast, after administration of BMS753951, strong enhancement of the stented and intermediate enhancement of the balloon injured coronary vessel segment were observed suggestive for vascular remodeling in the injured vessel segments (Figure 1c, f). There was no to little visually apparent enhancement in the control coronary artery
(Figure 1c). Quantitative analysis of vessel wall enhancement yielded a 3-fold higher CNR in the stented coronary artery when compared to the balloon injured and control artery ( $\mathrm{p}<0.001)$ (Figure 2 ). In addition, strong aortic and pulmonary vessel wall enhancement was seen after BMS753951 administration, which is in agreement with the high elastin content in those vessels, while no apparent enhancement was observed after Gd-DTPA injection $(\mathrm{p}<0.001)$ (Figure 3). ICP-MS of aortic samples yielded a gadolinium concentration of $0.29-0.52 \mathrm{mmol} / \mathrm{L}$.

\section{Conclusion}

This is the first MRI study to demonstrate the detection of ECM synthesis non-invasively in an animal model of coronary vessel wall injury using an elastin-specific contrast agent. This novel approach may be useful for in-vivo monitoring of vascular remodeling post stent placement or for the assessment of plaque burden in patients with suspected coronary artery disease.
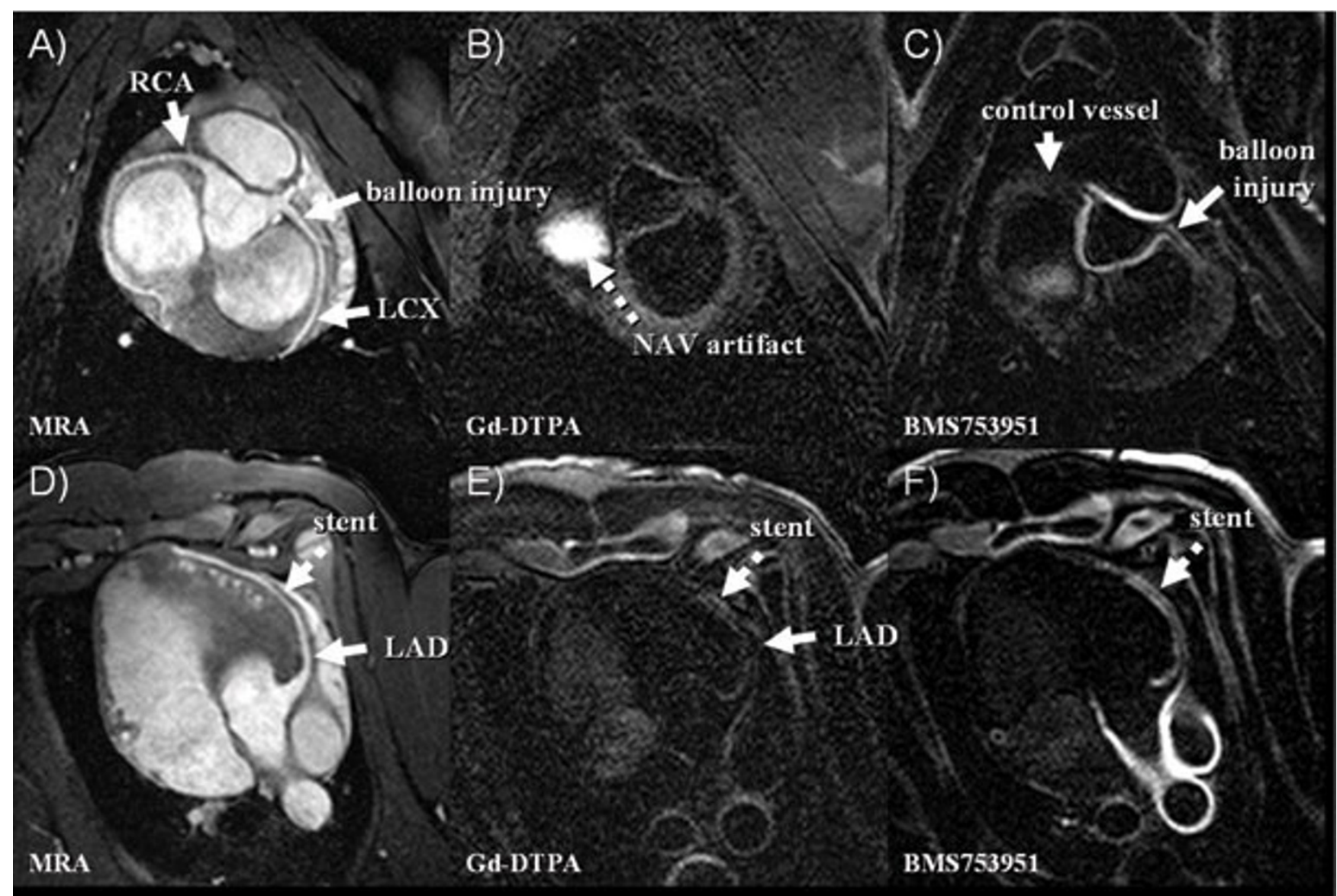

Figure 1: $(A, D)$ Coronary MRA of control (RCA), balloon injured (LCX), and stented vessel (LAD). Corresponding delayed enhancement images post injection of Gd-DTPA $(B, E)$ and BMS753951 (C, F).

\section{Figure I}




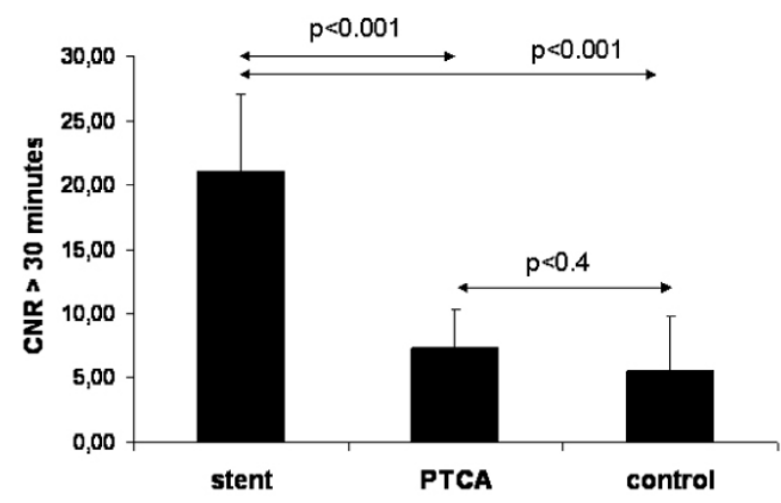

Figure 2

Contrast-to-noise ratio (CNR) in stented, balloon injured, and control vessel after administration of BMS75395I.



(B)

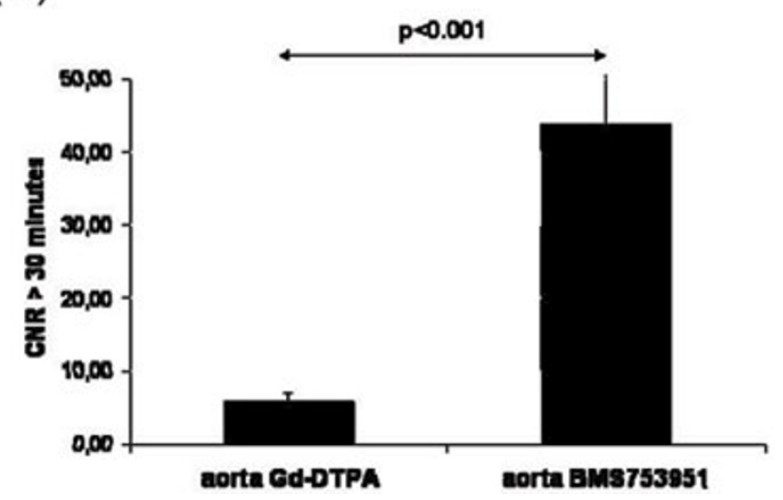

Figure 3

We sought to demonstrate the feasibility of imaging vascular remodeling in a porcine model of coronary injury using BMS75395I, a novel elastin-binding low molecular weight contrast agent. (A) Vessel wall enhancement in the descending aorta and aortic arch approximately 50 minutes post BMS75395I injection. (B) No apparent enhancement was observed after Gd-DTPA injection.
Publish with Bio Med Central and every scientist can read your work free of charge

"BioMed Central will be the most significant development for disseminating the results of biomedical research in our lifetime. "

Sir Paul Nurse, Cancer Research UK

Your research papers will be:

- available free of charge to the entire biomedical community

- peer reviewed and published immediately upon acceptance

- cited in PubMed and archived on PubMed Central

- yours - you keep the copyright

Submit your manuscript here:

http://www.biomedcentral.com/info/publishing_adv.asp
BioMedcentral 